\title{
Cerebral Blood Flow and Edema in Perinatal Hypoxic-Ischemic Brain Damage ${ }^{1}$
}

\author{
DENNIS J. MUJSCE, MELANIE A. CHRISTENSEN, AND ROBERT C. VANNUCCI \\ Department of Pediatrics (Neonatology and Neurology), The Milton S. Hershey Medical Center, \\ Pennsylvania State University, Hershey, Pennsylvania 17033
}

\begin{abstract}
The relationship between cerebral blood flow (CBF) and the evolution of brain edema was investigated in an experimental model of perinatal hypoxic-ischemic brain damage. Seven-d postnatal rats were subjected to unilateral common carotid artery ligation followed by $3 \mathrm{~h}$ of hypoxia with $8 \%$ oxygen at $37^{\circ} \mathrm{C}$. This insult produces neuronal necrosis and/or infarction only in the cerebral hemisphere ipsilateral to the arterial occlusion in the majority of animals; hypoxia alone produces no damage. CBF, measured by the indicator diffusion technique using iodo$\left[{ }^{14} \mathrm{Cl}\right.$-antipyrine, and tissue water content were determined concurrently in both cerebral hemispheres at specific intervals during recovery from cerebral hypoxia-ischemia. Water contents in the ipsilateral cerebral hemisphere were 89.1, 89.6, 89.7, 91.0, and 88.3\% at $30 \mathrm{~min}, 4 \mathrm{~h}, 24 \mathrm{~h}, 3 \mathrm{~d}$, and $6 \mathrm{~d}$, respectively $(p<0.001)$; whereas the percent tissue water in the contralateral hemisphere was unchanged from values in nonligated, hypoxic control rats $(87.7 \%)$. $\mathrm{CBF}$ was similar in both cerebral hemispheres at $30 \mathrm{~min}$, $4 \mathrm{~h}$, and $24 \mathrm{~h}$ of recovery $(50-65 \mathrm{~mL} / 100 \mathrm{~g} / \mathrm{min})$ and not different from age-matched controls. At 3 and $6 \mathrm{~d}, \mathrm{CBF}$ in the ipsilateral cerebral hemisphere was 30 and $26 \%$ of the contralateral hemisphere and 23 and $29 \%$ of the control animals, respectively $(p<0.001)$. No inverse correlation existed between the changes in brain water content and CBF at any interval until $6 \mathrm{~d}$ of recovery. Thus, an early hypoperfusion does not follow perinatal cerebral hypoxiaischemia, as occurs in adults. A late hypoperfusion takes place that results from rather than causes tissue necrosis seen histologically at $15-50 \mathrm{~h}$ of recovery. The results suggest that therapeutic attempts to improve CBF by reducing cerebral edema after hypoxia-ischemia will not alter ultimate neuropathologic outcome. (Pediatr Res 27: 450453,1990 )
\end{abstract}

\section{Abbreviation}

CBF, cerebral blood flow

A well-known accompaniment to the brain damage that results from perinatal hypoxia-ischemia is cerebral edema (1-4). Despite the close association between selective neuronal necrosis or infarction and brain swelling, it is not yet known whether edema is simply a byproduct of tissue injury or whether edema actually contributes to or accentuates brain damage. Studies in adult

Received November 20, 1989; accepted January 11, 1990.

Correspondence: Robert C. Vannucci, M.D., Department of Pediatrics, The Milton S. Hershey Medical Center, P.O. Box 850, Hershey, PA 17033.

Supported by Grant HD 19913 from The National Institute of Child Health and Human Development (R.C.V.).

'Presented in part at the annual meeting of the Society for Pediatric Research, Anaheim, CA, May 1987. animals have shown an inverse correlation between the development of cerebral edema and the appearance of a secondary or delayed hypoperfusion of the brain, which, in turn, might aggravate ultimate tissue injury (5-10). Taking the proposal one step further, Myers (11) has speculated, based on studies in the fetal monkey, that edema arises during the course of cerebral hypoxiaischemia, causing a persistent reduction in $\mathrm{CBF}$ and leading ultimately to tissue necrosis. Thus, cerebral edema may represent a critical event in the production of perinatal hypoxic-ischemic brain damage.

To resolve this important issue, we devised a set of experiments in an animal model of perinatal hypoxic-ischemic brain damage. The immature rat, in which brain damage can be readily produced by a combination of unilateral carotid artery occlusion and hypoxia with the inhalation of $8 \%$ oxygen, was chosen for study. A recently developed method to measure CBF in the immature rat was used concurrently with an analysis of the presence and extent of cerebral edema to ascertain the relationship of these two variables during recovery from hypoxia-ischemia.

\section{MATERIALS AND METHODS}

Dated pregnant Sprague-Dawley rats were purchased from Charles River (Wilmington, MA) and allowed to deliver spontaneously. Newborn rats were maintained with their dams until $7 \mathrm{~d}$ of postnatal age, at which time they underwent the procedures described below.

Induction of hypoxia-ischemia. To induce cerebral hypoxiaischemia, 7-d postnatal rats were anesthetized with halothane (4\% induction; $1.0-1.5 \%$ maintenance)- $30 \%$ oxygen-balance nitrous oxide, during which the neck was incised longitudinally in the midline for a length of $1 \mathrm{~cm}$. The right common carotid artery was identified, separated from contiguous structures, and permanently ligated with 4-0 surgical silk. The wound was closed with silk sutures and the animal allowed to recover from anesthesia. The entire surgical procedure lasted no more than 10 min. The rat pups were then returned to their dams for $4 \mathrm{~h}$, after which they were placed in $500-\mathrm{mL}$ airtight jars and exposed to a humidified gas mixture of $8 \%$ oxygen- $92 \%$ nitrogen for $3 \mathrm{~h}$. The jars were partially submerged in a $37^{\circ} \mathrm{C}$ water bath to maintain a constant thermal environment. The combination of unilateral carotid artery occlusion and hypoxia with $8 \%$ oxygen for $3 \mathrm{~h}$ has been shown to produce brain damage confined largely to the ipsilateral cerebral hemisphere in the vast majority of animals (12). Neither ligation nor hypoxia alone leads to brain damage; therefore, control animals were littermates that underwent only the latter procedure. After hypoxia-ischemia, the rat pups were returned to their dams until time of further experimentation.

Measurement of $C B F$. CBF was determined in litters of control and hypoxic-ischemic immature rats using an indicator fractionation technique previously described $(13,14)$. Specifically, individual rat pups received a subcutaneous injection of $5 \mu \mathrm{Ci}$ of iodo- $\left[{ }^{14} \mathrm{C}\right]$-antipyrine $(53 \mathrm{mCi} / \mathrm{mmol}$; New England Nuclear, 
Boston, MA). At either $0,10,20,30,45$, or $60 \mathrm{~s}$ after the injection, the animals (two to three at each interval) were decapitated and blood collected from the severed neck vessels into heparinized capillary tubes. Ten $\mu \mathrm{L}$ of blood were pipetted from the capillary tube into a scintillation vial containing $1 \mathrm{~mL}$ of Soluene-350 (United Technologies Packard, Downers Grove, IL). After mixing overnight in a mechanical shaker, the solution was combined with $9 \mathrm{~mL}$ of Dimilume-30 (United Technologies Packard). Samples then were counted on a Beckman LS-350 liquid scincillation counter (Beckman Instruments, Inc., Fullerton, CA) with appropriate blanks and standards. Mean blood radioactivities at each interval up to $60 \mathrm{~s}$ were determined to obtain the average arterial curve (see below).

The brains of two to three rats killed at 1 min were immediately removed from their skulls and samples $(\sim 25 \mathrm{mg})$ of each cerebral hemisphere in the vascular distribution of the middle cerebral artery were dissected and placed in tared scintillation vials. This region of brain was selected for analysis, since the brain damage arising from hypoxia-ischemia is most severe in the posterior aspect of the cerebral hemisphere ipsilateral to the carotid artery ligation (12). The scintillation vials were reweighed to ascertain the tissue wt, after which the brain specimens were solubilized overnight in $1 \mathrm{~mL}$ of Soluene-350. Nine $\mathrm{mL}$ of Dimilume-30 then was added to the solution and the entire contents isotopically counted.

CBF for each cerebral hemisphere was calculated from the average arterial curve and the tissue radioactivity at $60 \mathrm{~s}$ according to an equation derived from the Fick equation by Kety (15, 16):

$$
\mathrm{C}_{\mathrm{B}}(\mathrm{T})=\lambda \cdot \mathrm{K} 0^{\int \mathrm{T}} \mathrm{C}_{\mathrm{A}} \cdot \mathrm{e}^{-\mathrm{K}(\mathrm{T}-\mathrm{t})} \mathrm{dt} \times 100
$$

where $C_{B}(T)=$ concentration of tracer in the brain at time $T$ $(\mathrm{dpm} / \mathrm{g}), \lambda=$ brain:blood partition coefficient for iodo-antipyrine $(\mathrm{mL} / \mathrm{g})=0.94(13), \mathrm{C}_{\mathrm{A}}=$ concentration of tracer in blood $(\mathrm{dpm} /$ $\mathrm{mL}), \mathrm{T}=$ time at end of experiment $(1 \mathrm{~min})$, and $\mathrm{t}=$ sometime between 0 and $T$. To solve the equation, a series of substitutions was made for $\mathrm{K}$ on an IBM personal computer (IBM Instruments, Inc., Danbury, CT). The value of the integral was estimated using the trapezoid rule. The value of $\mathrm{K}$ providing the calculated value of $C_{B}(T)$ closest to the observed value provided the solution. This $\mathrm{K}$ multiplied by $\lambda \times 100=$ blood flow in $\mathrm{mL} /$ $100 \mathrm{~g} / \mathrm{min}$.

Determination of brain water content. Samples (75-100 mg) of each cerebral hemisphere immediately adjacent to those specimens obtained for determination of CBF (see above) were dissected and placed in tared 5-mL glass vials and weighed on a microanalytical balance. Subsequently, the tissue specimen was dessicated at $70^{\circ} \mathrm{C}$ for $48 \mathrm{~h}$. Reweighing of the vial ascertained the hemispheric dry wt, and by subtraction from the total hemispheric wt, the wet wt of the tissue was obtained. Water content was determined as a percentage of total hemispheric wt according to the formula:

$$
\text { Water content }(\%)=\frac{\text { total } w t-\text { dry wt }}{\text { total } w t} \times 100
$$

Statistical methods. Statistical methods used to analyze the data included the paired and unpaired $t$ test and a correlation of coefficients analysis.

\section{RESULTS}

Immature rats underwent concurrent measurements of cerebral hemispheric water content and CBF at $30 \mathrm{~min}, 4$ and $24 \mathrm{~h}$, and 3 and $6 \mathrm{~d}$ of recovery from cerebral hypoxia-ischemia (Figs. 1 and 2). Littermate controls (hypoxia without arterial ligation) underwent identical procedures at the same intervals. Water content of the cerebral hemisphere ipsilateral to the carotid artery occlusion was increased $(p<0.001)$ above mean values of either cerebral hemisphere of control animals already at $30 \mathrm{~min}$ of
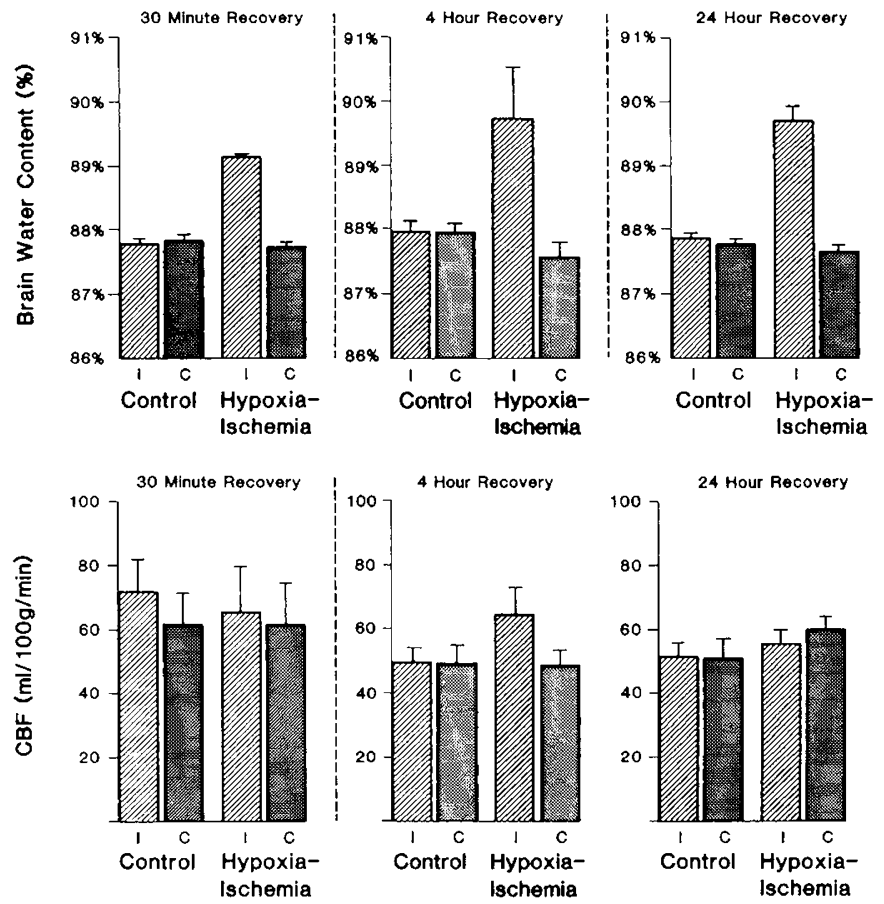

Fig. 1. Water contents as percent of total tissue wt and CBF of the cerebral hemispheres ipsilateral $(I)$ and contralateral $(C)$ to common carotid artery occlusion of 7-d postnatal rats at $30 \mathrm{~min}, 4$, and $24 \mathrm{~h}$ of recovery from hypoxia-ischemia. Control animals underwent hypoxia without prior arterial ligation. Bars represent means of 10,9 , and 22 animals at $30 \mathrm{~min}, 4$, and $24 \mathrm{~h}$, respectively; vertical lines denote \pm 1 SEM.

recovery and remained significantly elevated for up to $3 \mathrm{~d}$ posthypoxia-ischemia $(p<0.001)$. A slightly increased water content $(p<0.05)$ was still apparent at $5 \mathrm{~d}$ of recovery. Water content of the nonischemic, contralateral cerebral hemisphere was near identical to those of the age-matched control hemispheres at all measured intervals $(p>0.05)$. The slow decline in the percent tissue water of the control brains from 7 to 13 postnatal $\mathrm{d}$ is an age effect (17).

Despite the early and sustained increase in water content of the ipsilateral cerebral hemisphere, CBF was not different from either the contralateral or control cerebral hemispheric values at $30 \mathrm{~min}$ and $24 \mathrm{~h}$ of recovery $(p>0.05)$ (Fig. 1). CBF was actually higher by $25 \%$ at $4 \mathrm{~h}(p<0.05)$. By 3 and $6 \mathrm{~d}$ posthypoxiaischemia, a substantial reduction in ipsilateral CBF had occurred such that blood flows were 30 and $26 \%$ of the contralateral cerebral hemisphere and 23 and $29 \%$ of control brains, respectively ( $p<0.001)$ (Fig. 2). No inverse correlation existed between $\mathrm{CBF}$ and the changes in water content at any interval until $6 \mathrm{~d}$ of recovery (Fig. 3).

\section{DISCUSSION}

Our findings indicate that cerebral edema is a prominent feature of the brain damage that arises from unilateral common carotid artery occlusion combined with $3 \mathrm{~h}$ of hypoxia in the immature rat $(12,18)$. The increase in water content, equivalent to cerebral edema, is initiated as an early posthypoxic-ischemic event that continues for up to $3 \mathrm{~d}$ of recovery. A vasogenic component to the edema is present, as documented by a previous study (18) in which both horseradish peroxidase and Evan's blue dye readily extravasate from the blood stream into the parenchyma of the damaged cerebral hemisphere. Despite its presence, the extent to which cerebral edema is critical to produce or accentuate hypoxic-ischemic tissue injury has yet to be fully clarified.

Superficially, the changes in water content of the hypoxic- 

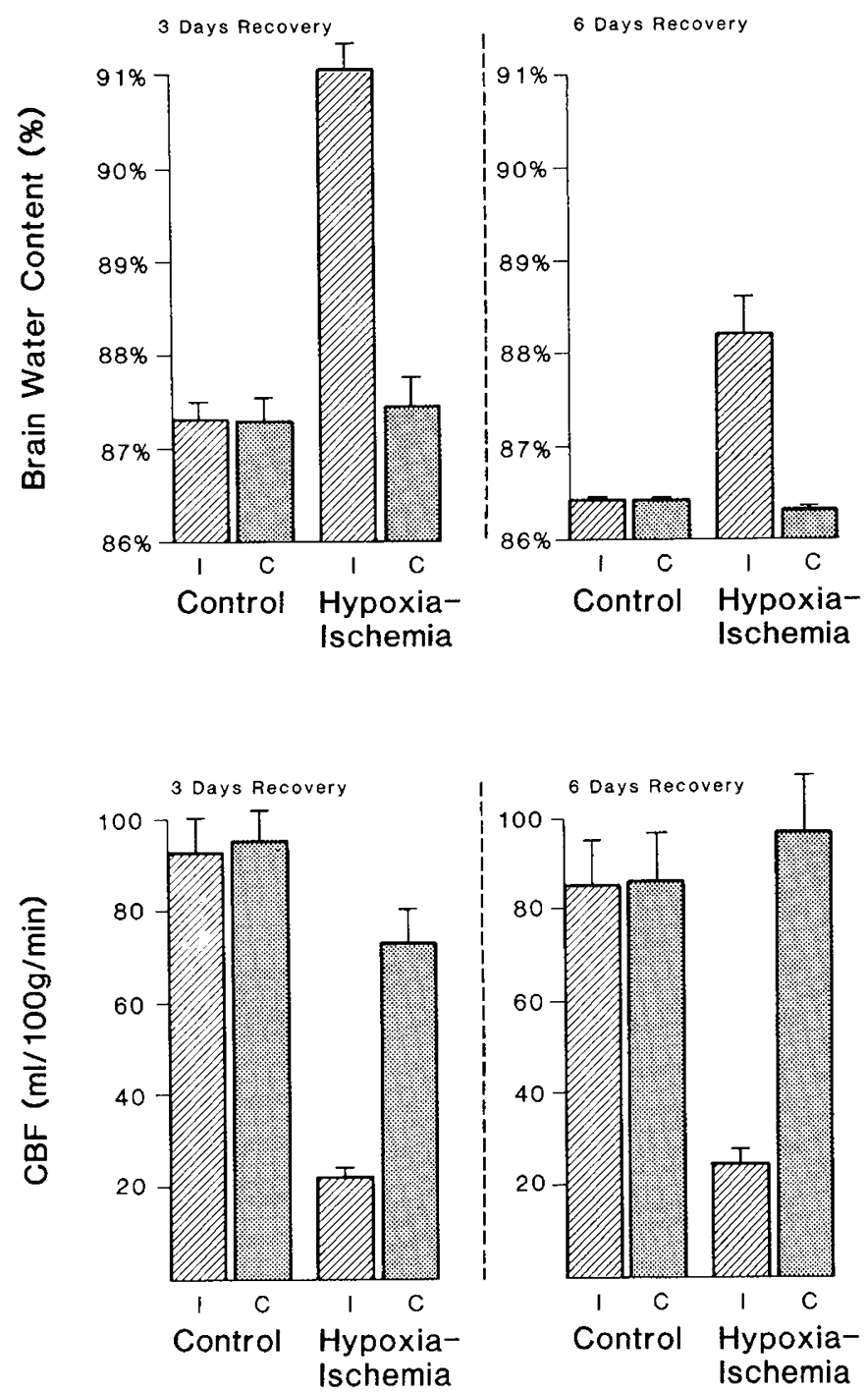

Fig. 2. Water contents as percent of total tissue wt and $\mathrm{CBF}$ of the cerebral hemispheres ipsilateral $(I)$ and contralateral $(C)$ to common carotid artery occlusion of 7-d postnatal rats at 3 and $6 \mathrm{~d}$ of recovery from hypoxia-ischemia. Control animals underwent hypoxia without prior arterial ligation. Bars represent means of 11 and 12 animals at 3 and $6 \mathrm{~d}$, respectively; vertical lines denote \pm 1 SEM.

ischemic cerebral hemisphere appear rather modest, i.e. the maximal percent increase at $72 \mathrm{~h}$ of recovery was only $104 \%$ of the control value. However, a $4 \%$ increase in tissue water equates to a substantial increase in brain volume (19). Specifically:

$\%$ increase in brain volume $=$

$$
\frac{\% \text { dry wt (control) }-\% \text { dry wt (hypoxia-ischemia) }}{\% \text { dry wt (hypoxia-ischemia) }} \times 100
$$

or

$$
\frac{12.3-9.0}{9.0} \times 100=37 \%
$$

Thus, when cerebral edema was maximal, the hypoxic-ischemic cerebral hemisphere was $37 \%$ larger than the contralateral hemisphere or either hemisphere of the control animals.

The major question to be resolved by our investigation was whether or not cerebral edema occurs to a degree sufficient to compromise the cerebral circulation during recovery from hypoxia-ischemia. A secondary hypoperfusion of the brain, in turn, might perpetuate metabolic perturbations that contribute to ul-

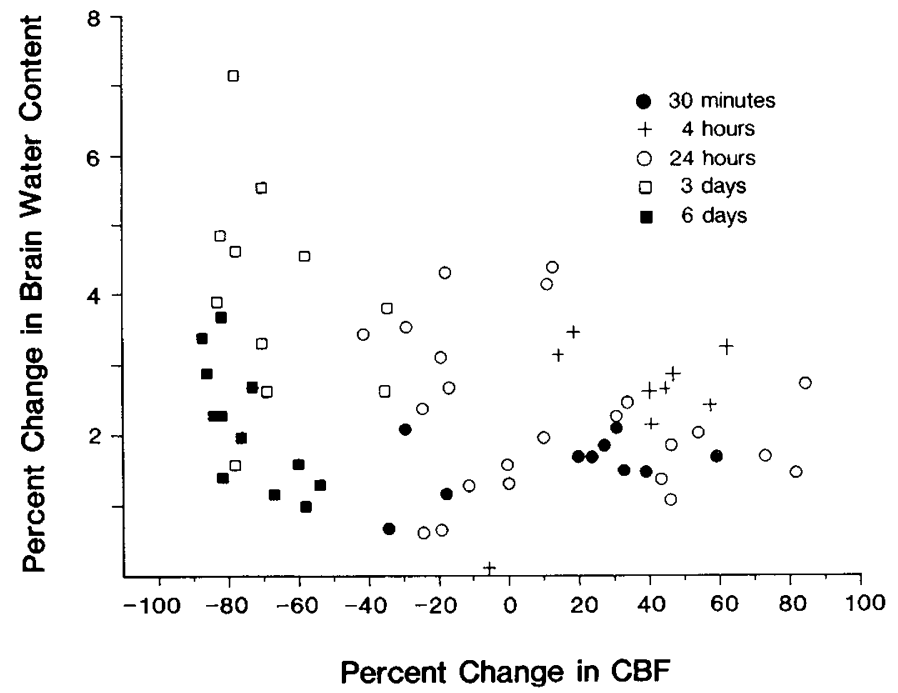

Fig. 3. Relationship between water content of and blood flow to the cerebral hemisphere ipsilateral to the common carotid artery occlusion of 7-d postnatal rats during recovery from hypoxia-ischemia. Symbols represent individual values for the percent change in tissue water content and in $\mathrm{CBF}$ from mean control values. No statistical relationship existed between the variables at any time of recovery except at $6 \mathrm{~d}$, where $r=$ $0.68 ; p<0.02$ by a correlation of coefficients analysis.

timate tissue injury. The results presented here indicate that such is not the case, at least for immature rat brain, because despite substantial swelling of the hypoxic-ischemic cerebral hemisphere, CBF remained well within the normal range for up to $24 \mathrm{~h}$ of recovery. Thus, an early hypoperfusion does not occur, as has been shown in adult animals $(6-10)$. Rather, a late hypoperfusion takes place that results from rather than causes tissue necrosis, as histologically confirmed brain damage is maximal at $15-50 \mathrm{~h}$ of recovery (12).

Why does an early postischemic hypoperfusion not occur in the immature rat in the setting of brain damage and cerebral edema which is equal to or greater than that of the mature animal (23)? In adult rodents subjected to either complete or incomplete cerebral ischemia sufficient to produce brain damage, perturbations in CBF measured with diffusible indicators persist well into the recovery period $(7,8,10)$. Initially, there is a brief phase of cerebral hyperemia followed thereafter by hypoperfusion that lasts up to $24 \mathrm{~h}$ postischemic insult. The secondary or delayed hypoperfusion may be of a degree sufficient to render the brain vulnerable to additional ischemic damage.

Unlike our findings, an early hypoperfusion of the brain after hypoxia-ischemia has been observed in newborn sheep $(20,21)$. Rosenberg et al. $(20,21)$ subjected lambs to partial asphyxia, after which CBF and the cerebral metabolic rate for oxygen were depressed by 37 and $30 \%$ of control, respectively, within $4 \mathrm{~h}$ of recovery. In this investigation, $\mathrm{CBF}$ was measured with radiolabeled microspheres rather than with a diffusible indicator, as in our study. Strictly speaking, microspheres would reflect blood cell flow to the brain, whereas a diffusible indicator would be more representative of plasma flow. Therefore, the apparent conflicting results of our study in rats and those in the newborn lamb might relate entirely to the differing techniques used to measure CBF. Another explanation for the descrepant results is the variation in the maturity of the animal brain at the time of experimentation. The functional and anatomic maturity of the sheep brain is advanced at birth relative to the 7 -d postnatal rat (22). Accordingly, differences in the reactivity of cerebral blood vessels to posthypoxic-ischemic metabolic stress might account for the observed discrepancies in the CBF responses to cerebral hypoxia-ischemia in the two species (see below). Whatever the reason, it must be emphasized that only in the immature rat has 
CBF been measured in the setting of an insult known to produce overt brain damage.

The pathophysiologic mechanism(s) leading to the secondary hypoperfusion of the previously ischemic adult brain undergoing damage is not entirely understood. Increased vascular resistance secondary to edematous swelling of astrocytic foot processes, which surround parenchymal capillaries, certainly plays a role (23-25). Metabolic factors, especially a postischemic imbalance between mediators of vasodilation $\left(\mathrm{H}^{+}\right.$ions, adenosine, prostacyclin) and vasoconstrictors (catacholamines, thromboxane $\mathrm{A}_{2}$ ) might contribute to aberrant cerebral vascular tonus (26-29). These factors may not be fully operative in immature rat brain, thereby allowing for a relatively stable blood flow pattern in the posthypoxic-ischemic period.

Mechanical factors must also be considered to explain the agespecific cerebral vascular responses to recovery from hypoxiaischemia. In this regard, the brain swelling represented by increases in water content that characterize the immature rat is accommodated, at least in part, by a widening of its elastic sutures, a depression of the tentorium cerebellum, and moderate herniation of the cerebellar vermis (12). The ability of these forms of internal decompression would serve to minimize increases in intracranial pressure and its consequent effect on cerebral perfusion. Such internal decompression cannot be accomplished in the adult animal with its bony calvarium and rigid dural membranes.

Support for the notion of an internal decompression of the edematous immature brain is derived from investigations in human infants in whom cerebral edema arises as a consequence of an asphyxial insult at birth. First, clinical experience dictates that cerebral herniation arising from brain infarction and edema is a rare occurrence in the newborn infant, whereas herniation is not an uncommon accompaniment to stroke in adults (30). Second, recent clinical investigations have shown that asphyxiated newborn infants who exhibit evidence of cerebral edema on CT scan manifest only modest or no elevation in intracranial pressure and no decrease in cerebral perfusion pressure (mean arterial blood pressure-intracranial pressure) $(31,32)$. Thus, as in the immature rat, hypoxic-ischemic brain swelling in the newborn human infant is not associated with any major disruption of the cerebral circulation so long as systemic blood pressure is maintained (31). Any therapy to improve CBF by reducing cerebral edema after cerebral hypoxia-ischemia should not alter ultimate neuropathologic outcome (33).

\section{REFERENCES}

1. Clifford SH 1941 The effects of asphyxia on the newborn infant. J Pediatr 18:567-578

2. Pryse-Davis J, Beard RW 1972 A necropsy study of brain swelling in the newborn with special reference to cerebellar herniation. J Pathol 109:51-56

3. Anderson JM, Belton NR 1974 Water and electrolyte abnormalities in the human brain after severe intrapartum asphyxia. J Neurol Neurosurg Psychiatry 37:514-520

4. Larroche JCL (ed) 1977 Developmental Pathology of the Neonate. Elsevier, North Holland, Amsterdam

5. Hossmann KA, Zimmerman V 1974 Resuscitation of the monkey brain after
$1 \mathrm{~h}$ complete ischemia. I. Physiological and morphological observations. Brain Res 81:59-74

6. Snyder JV, Nemoto EM, Carroll RG, Safar P 1975 Global ischemia in dogs: intracranial pressure, brain blood flow and metabolism. Stroke 6:21-27

7. Levy DE, Van Uitert RL, Pike CL 1979 Delayed postischemic hypoperfusion a potential damaging consequence of stroke. Neurology 29:1245-1252

8. Crockard A, lannotti F, Hunstock AT, Smith RD, Harris RJ, Symon L 1980 Cerebral blood flow and edema following carotid occlusion in the gerbil. Stroke 11:494-498

9. Miller CL, Lampard DG, Alexander K, Bronin WA 1980 Local cerebral blood flow following transient cerebral ischemia. Stroke 11:534-541

10. Kägström E, Smith ML, Siesjö BK 1983 Local cerebral blood flow in the recovery period following complete cerebral ischemia in the rat. $\mathrm{J}$ Cereb Blood Flow Metab 3:170-182

11. Myers RE 1977 Experimental models of perinatal brain damage: relevance to human pathology. In: Gluck L (ed) Intrauterine Asphyxia and the Developing Fetal Brain. Yearbook Medical Publishers, Chicago, pp 37-96

12. Rice JE, Vannucci RC, Brierley JB 1981 The influence of immaturity on hypoxic-ischemic brain damage in the rat. Ann Neurol 9:131-141

13. Lyons DT, Vasta F, Vannucci RC 1987 Autoradiographic determination of regional cerebral blood flow in the immature rat. Pediatr Res 21:471-476

14. Vannucci RC, Lyons DT, Vasta F 1988 Regional cerebral blood flow during hypoxia-ischemia in immature rats. Stroke 19:245-250

15. Kety SS 1951 Theory and applications of the exchange of inert gas at the lungs and tissues. Pharmacol Rev 3:1-41

16. Kety SS 1960 Measurement of local cerebral blood flow by the exchange of an inert, diffusible substance. Methods Med Res 8:228-236

17. Donaldson HH 1916 A revision of the percentage of water in the brain and in the spinal cord of the albino rat. J Comp Neurol 27:77-115

18. Vannucci RC 1985 Pathogenesis of perinatal hypoxic-ischemic brain damage. In: Thompson RA, Green JR, Johnsen SD (eds) Perinatal Neurology and Neurosurgery. Spectrum Publications, New York, pp 17-39

19. Elliott KAC, Jasper H 1949 Measurement of experimentally induced brain swelling and shrinkage. Am J Physiol 157:122-129

20. Rosenberg AA 1986 Cerebral blood flow and $\mathrm{O}_{2}$ metabolism after asphyxia in neonatal lambs. Pediatr Res 20:778-782

21. Rosenberg AA, Murdaugh E, White CW 1989 The role of oxygen-free radicals in postasphyxia cerebral hypoperfusion in newborn lambs. Pediatr Res 26:215-219

22. Vannucci RC Perinatal brain metabolism. In: Polin RA, Fox WW (eds) Neonatal and Fetal Medicine: Physiology and Pathophysiology. Saunders, Orlando (in press)

23. Brown AW, Brierley JB 1973 The earliest alterations in rat neurones and astrocytes after anoxia-ischaemia. Acta Neuropathol 23:9-22

24. Brown AW 1977 Structural abnormalities in neurones. J Clin Pathol 30 (suppl II): $155-169$

25. Fischer EG, Ames A, Hedley-Whyte ET, O'Gormans 1977 Reassessment of cerebral capillary changes in acute global ischemia and their relationship to the "no reflow phenomenon." Stroke 8:36-39

26. Siesjö BK 1978 Brain Energy Metabolism. Wiley, Chichester, England

27. Hallenbeck JM, Furlow TW 1979 Prostaglandin $\boldsymbol{I}_{2}$ and indomethacin prevent impairment of post-ischemic brain perfusion in the dog. Stroke 10:629-637

28. Winn HR, Rubio R, Berne RM 1981 The role of adenosine in the regulation of cerebral blood flow. J Cereb Blood Flow Metab 1:239-244

29. Stevens MK, Yaksh TL, Hansen RB, Anderson RE 1986 Effect of preischemic cyclooxygenase inhibition of zomepirac sodium on reflow, cerebral autoregulation, and EEG recovery in the cat after global ischemia. J Cereb Blood Flow Metab 6:691-702

30. Plum F, Posner JB 1980 The Diagnosis of Stupor and Coma. FA Davis Co, Philadelphia

31. Clancy R, Legido A, Newell R, Bruce D, Baumgart S, Fox WW 1988 Continuous intracranial pressure monitoring and serial electroencephalographic recordings in severely asphyxiated term neonates. Am J Dis Child 142:740747

32. Lupton BA, Hill A, Roland EH, Whitfield MF, Flodmark O 1988 Brain swelling in the asphyxiated term newborn: pathogenesis and outcome. Pediatrics 82:139-146

33. Mujsce DJ, Stern DR, Vannucci RC, Towfighi J 1988 Mannitol therapy in perinatal hypoxic-ischemic brain damage. Ann Neurol 24:349A(abstr) 